\title{
Priming Relationship Schemas: My Advisor and the Pope Are Watching Me from the Back of My Mind
}

\author{
MARK W. BaLDWIN \\ Research Center for Group Dynamics \\ AND \\ Suzanne E. Carrell and David F. Lopez \\ University of Waterloo, Ontario, Canada \\ Received April 10, 1989
}

\begin{abstract}
Cognitive priming methodologies were employed to examine whether internally represented interpersonal information can affect the experience of self. In the first study, psychology graduate students evaluated their own research ideas after exposures, below the level of conscious awareness, to slides of either the scowling, disapproving face of their department chair or the approving face of another person. In the second study, Catholic subjects evaluated themselves after exposure to the disapproving face of either the Pope or an unfamiliar other. In both studies, self-ratings were lower after the presentation of a disapproving significant other. In Study 2 there was no effect, however, if the disapproving other was not a personally significant authority figure, either because the subject was a relatively nonpracticing Catholic or the picture was of an unfamiliar person. It is argued that the primes may have activated relationship schemas, or cognitive structures representing regularities in interpersonal interaction. () 1990 Academic Press, Inc
\end{abstract}

A person's sense of self at any given moment is surely influenced by a broad range of factors, including stable self-concepts, recent experi-

Study 1 was supported by a Social Sciences and Humanities Research Council of Canada postdoctoral fellowship to Mark Baldwin, and was conducted while he was at the Research Center for Group Dynamics of the University of Michigan. Study 2 was the basis for the honors theses of David Lopez and Suzanne Carrell at the University of Waterloo. We thank John Ellard and Bob Zajonc for their help in the preparation of stimuli in Study 1, and John Holmes for his assistance in conducting Study 2. Correspondence should be addressed to Mark Baldwin, Department of Psychology, University of Winnipeg, 515 Portage Avenue, Winnipeg, Manitoba, Canada R3B 2E9. 
ences, social roles, and various context effects. Many theorists (e.g., Mead, 1934; Sullivan, 1953), however, have held that the major determinant of how self is construed is how the person believes he or she would be regarded by significant others. Self-evaluation, for example, is assumed to involve a reflected appraisal process whereby self is assessed according to how significant others would likely respond.

The process of reflected appraisal is an ideal candidate for a social cognitive analysis, which ultimately could focus on how information about one's significant relationships is perceived, interpreted, stored, and recalled. The studies to be presented here represent a preliminary attempt at applying priming methodologies to a more modest goal, which was to examine how salient, internally represented interpersonal information can affect the experience of self.

Baldwin and Holmes (1987) used cognitive priming methodologies to assess the impact of internally represented significant others on the experience of self. In the context of a guided visualization experiment, undergraduate women subjects first visualized the faces of either two older members of their family (e.g., their parents) or two associates from campus. Ten minutes later, under the guise of a separate study, they rated the enjoyableness of some written passages. One passage described a sexual encounter, and represented a fairly permissive attitude toward sexuality. The prediction was that subjects' responses to this sexual passage would be influenced by evaluative standards associated with whichever private audience had been primed. As expected, those women who had been primed to experience themselves in relation to their parents rated the story as significantly less enjoyable than those who previously had visualized their (presumably more permissive) friends from campus.

An important assumption in the work just reviewed was that a visualization prime could act as a cue for cognitive structures representing one's significant others and one's relationships with them. If interpersonal information is indeed represented in cognitive structure, it should be possible to access it with minimal primes (Higgins \& King, 1981). An extremely subtle cognitive priming technique involves the use of very brief stimulus exposures, and recent research has shown that it is possible to prime, below the level of subjects' conscious awareness, a wide range of phenomena. Bargh and Pietromonaco (1982), for example, used 100ms parafoveal exposures of adjectives such as "hostile" and "unfriendly" to influence subjects' perceptions of a stimulus person. Robles, Smith, Carver, and Wellens (1987) exposed subjects to 17-ms exposures of frightening scenes, and observed an increase in subjects' level of anxiety. Bornstein, Leone, and Galley (1987) observed a mere exposure effect when subjects were given 4-ms exposures of emotionally neutral pictures of unfamiliar people's faces.

In an attempt to use similar methods to prime reflected appraisal in- 
formation, we gave subjects brief exposures to pictures of significant authority figures' faces, and then observed effects on subjects' momentary sense of self. One of the most basic interpersonal experiences, and the one studied here, is the experience of social disapproval. Sullivan (1953) held that because of the psychological importance of maintaining secure relationships, people are motivated to learn what types of behavior produce positive and negative responses from others. He argued that experiences of approval and disapproval from significant others form a bedrock of interpersonal contexts which guide the processing of information about self, and to which specific acceptable and unacceptable aspects of self are assimilated. Certainly the process of self-evaluation, with its implications for affect and self-esteem, is an extremely important aspect of self-conception.

Speculations about the cognitive processes involved in the priming of reflected appraisal information will be reserved for the general discussion; first, it is necessary to establish that there is a reliable phenomenon to be discussed. In the studies to be reported here, stimuli representing disapproval by significant authority figures were presented as primes below the level of subjects' awareness. Predictions were that individuals' self-evaluations would be more negative and self-critical following disapproval primes.

\section{STUDY 1}

In the first study, psychology graduate students evaluated their own research ideas after 2-ms exposures to slides of either disapproving or approving faces. In preparing the stimulus slides, it seemed preferable to photograph individuals who would be truly significant evaluative others for the experimental subjects. In many situations, there are usually one or two individuals who are consensually perceived as evaluators. After chatting with some graduate students at the Research Center for Group Dynamics, it became clear that a major evaluative authority figure for them was Robert Zajonc. Bob is the director of the department, is a renowned and respected social psychologist, and was affectionately regarded by the students as someone who could be counted on to ask the toughest questions when one was giving a talk or presentation of some kind. He was definitely a person who might be "in the back of their mind" when they were working on an idea or trying to decide if it was really any good or not.

Bob graciously agreed to serve as a disapproving stimulus, but suggested that given his reputation among the students as a patriarch of sorts it might be advisable to ask someone else to provide the approving expression. This seemed a wise route to go for a preliminary study, and John Ellard, then a postdoctoral fellow at Michigan who was familiar to the subjects, graciously agreed to supply a positive expression. The 
approving and disapproving stimuli were exposed to the students during a bogus reaction-time task, after which they evaluated the quality of their own research ideas.

There are some unresolved questions in the literature regarding the most appropriate methods and criteria for studying automatic priming effects (see Holender, 1986, for a recent review). For example, many studies include a task in which subjects are asked to discriminate one stimulus from another, on the assumption that if there is not a statistically significant degree of discrimination it can be concluded that the stimuli are below threshold. Cheesman and Merikle (1985) argue, however, that when discrimination is measured properly and thoroughly, typically using hundreds of trials, stimuli that truly cannot be discriminated also do not produce any priming results on other measures. These authors contend that subliminal primes are those that could produce discrimination results (if measured adequately), but that are at a level where subjects report not being aware of them; that is, they are below the individuals' subjective threshold for consciousness. In other words, the proper criterion for determining the threshold of conscious perception is not chance performance on a discrimination task, but rather the subjects' own selfreports of awareness. A second methodological issue is whether exposure times are best set at a single value for all subjects, or whether perception thresholds should be determined separately for each individual. Due to the unusual nature of the primes used in the present studies (pictures of familiar others' faces), it seemed undesirable to perform hundreds of discrimination trials in order to set individual thresholds prior to the experimental presentations, as this would alert subjects to the nature of the stimuli and might dilute the effects of interest. Because our interest was primarily in the interpersonal content of the primes, rather than in resolving ongoing methodological debates, we elected to employ pilot subjects' subjective reports of awareness (following Cheesman and Merikle's distinction) to set a single exposure time for each study. Experimental subjects' reports of awareness were also assessed to ensure that no subject could accurately report on the nature of the stimuli.

\section{Method}

\section{Subjects}

Sixteen (eight male, eight female) graduate students and one (female) postdoctoral fellow, affiliated with the Research Center for Group Dynamics, volunteered to participate in the study. Their mean age was 26.1 years. One subject's data were discarded due to an equipment malfunction. Subjects were randomly assigned to condition, with the restriction that there be an equal number (8) per cell. Subjects were run indjvidually by a male experimenter. 


\section{Apparatus}

Two Kodak carousel projectors were used to present the stimulus and masking slides. Slides were projected on a wall $4.5 \mathrm{~m}$ directly in front of the subject, forming an image $.65 \mathrm{~m}$ square. An IBM-XT computer recorded reaction times and controlled Lafayette and Uniblitz shutter timers. which, in turn, controlled two Uniblitz electronic shutters.

\section{Stimulus Presentations}

Previous researchers in the area have used exposures from $4 \mathrm{~ms}$ (e.g., Silverman, 1983) to $100 \mathrm{~ms}$ (e.g., Bargh \& Pietromonaco, 1982) for stimulus presentations. Most of this work has involved presentation of words or phrases, however, with longer presentations typically outside the foveal visual field to ensure subliminality. Some researchers (e.g., Kunst-Wilson \& Zajonc, 1980; Shevrin, Smith, \& Frizler, 1971) have used exposures as short as $1 \mathrm{~ms}$ when stimuli were pictorial. With the centrally presented pictures of faces used in this study, it was necessary to use shutter settings of no more than 2 ms to ensure that pilot subjects could not report on the nature of the stimulus. Pilot subjects were tested under the same lighting conditions as the experimental subjects, and using multiple exposures. With a 2 -ms presentation, ${ }^{1}$ immediately followed by a 10 -ms exposure of a masking slide (a collage of brightly colored shapes), pilot subjects uniformly denied awareness of a first slide, reporting seeing only the mask. When asked to guess what the slide had been, the modal response was that the stimulus was an "abstract painting", reflecting an awareness of only the mask. Cheesman and Merikle (1985) have argued that self-reports provide the best test of conscious awareness; thus the presentation was short enough and adequately masked to be considered out of awareness.

Stimulus presentations consisted of four exposures in succession, with 5-s intervals between exposures.

\section{Procedure}

Subjects first were asked to jot down key words to describe three of the most recent research ideas that they had been working on. They were told they would not be asked to describe the ideas in any detail, but later would need to refer back to remind them of the ideas they had chosen. The selection of ideas came at this point of the procedure so it could not be influenced by later experimental manipulations.

The procedure for the study was then explained as a series of exercises in which subjects would be evaluating their ideas, and doing some reaction-time tasks. The reaction time task would involve pressing a button as quickly as possible after seeing a flash of light on the wall they were facing. No rationale was given for the two tasks; subjects were told that the purpose of the study would be explained at the end of the session (debriefing revealed that to the extent that subjects generated hypotheses about the two tasks, they assumed that the purpose was to see if the positivity of their self-evaluations would affect their reaction times).

The experimenter left the room at this point, to avoid the possibility of biasing in some way the subject's evaluative responses, and the remainder of the study was directed by audiotaped instructions uniform for all subjects. Also, random assignment to experimental

\footnotetext{
' Although the shutter was set at $2 \mathrm{~ms}$, it may be that the rise time for the shutter to be activated and deactivated makes the actual exposure time somewhat unreliable, and possibly longer. The onset of the masking stimulus was $2 \mathrm{~ms}$ after the onset of the experimental stimulus, however (as both were computer-controlled), so even if the stimulus was exposed longer it would have been degraded after that point.
} 
conditions (i.e., order of slide presentation, see below) was done after the experimenter left the room, to allow the experimenter to remain blind to condition during initial phases when interaction was required.

Subjects then performed a series of reaction time trials, during which the masked priming stimuli were presented. The three stimuli included a blank slide of orange color; the scowling, disapproving face of Robert Zajonc, the director of their progran; and the smiling, approving visage of John Ellard, a postdoctoral fellow. In both pictures, the person was looking directly at the camera. The room lights were dimmed during stimulus presentations.

All subjects were exposed to the blank slide first, in order to establish that there were no pretreatment differences between groups. After four exposures of this slide, they evaluated the first of their research ideas they had indicated earlier. They marked slashes across $100-\mathrm{mm}$ lines to indicate their response to the following questions: How good an idea do you feel this is, overall? (not very good/very good); How important an idea is this? (not very important/very important); How original an idea is this? (not very original/very original): How much do you like this idea? (not very much/very much). Last, subjects graded their idea out of $100 \%$.

During the next reaction-time task, half the subjects were exposed to the approval stimulus and half were shown the disapproval stimulus, after which they evaluated their second idea. Finally, they were exposed to the remaining stimulus, and they evaluated their third idea.

After the three ideas had heen evaluated, the smiling slide was presented again to all subjects as part of a fourth reaction time trial in an attempt to counteract any negative effects of the disapproving slide. Prior to debriefing, subjects were asked to guess what had been flashed on the screen. Their responses mirrored those of the pilot subjects: They suggested such things as an abstract painting, a house, the letter $\mathbf{E}$, and an axe, all apparently suggested by shapes in the mask. No subject was able to report on the actual nature of the experimental stimuli. Subjects then were debriefed and thanked for their participation.

\section{Results}

Each of the $100-\mathrm{mm}$ line scales was converted to a score out of 100 by measuring the distance of the subject's slash, in $\mathrm{mm}$, from the negative endpoint. The five rating scales (how good, important, original, and liked the idea was, plus the percentage grade) showed high intercorrelations, average pairwise $r=.63$, so each subject's ratings were averaged to yield one score out of one hundred for each idea. High numbers indicated generally positive evaluations.

Given the lack of statistical power imposed by the necessarily limited sample size, planned comparisons were used as the most direct method of testing whether the subliminal presentations of evaluative primes had the intended effect. As predicted, the score subjects gave their idcas tended, overall, to be higher following a presentation of the approval stimulus, $M=79.9$ out of 100 , than following their chairman's scowling face, $M=72.7, t(15)=1.84, p<.05$ (one-tailed). As shown in Table 1 , however, this effect is most evident after the first experimental prime. Indeed, it is not clear whether the ratings of the final idea were affected by the second face slide at all, or whether perhaps the effects of the first prime simply dissipated. Theoretically it would not be a confident 
TABLE 1

Idea Evaluations ay Stimulus and Order of Presentation

\begin{tabular}{lccc}
\hline & & \multicolumn{1}{c}{ Stimulus } \\
\cline { 2 - 4 } $\begin{array}{l}\text { Order of stimulus } \\
\text { presentation }\end{array}$ & Pretest & First face & Second face \\
\hline Approval/disapproval & 74.2 & 82.8 & 77.7 \\
Disapproval/approval & 71.3 & 67.8 & 77.0 \\
\hline
\end{tabular}

Note. Numbers represent ratings out of 100 , with higher numbers representing more positive ratings.

prediction that a second presentation would override completely the structure accessed by the first. Focusing only on the first prime, then, there is a difference between those subjects exposed to the approving face, $M=82.8$, and those exposed to the disapproving face, $M=67.8$, $t(14)=1.97, p<.05$ (one-tailed). This difference of 15 percentage points is sizable; in fact it is approximately equivalent to one standard deviation $(s=15.28)$.

As anticipated, there were no premanipulation differences between the groups, $t<1$. There were also no significant effects on reaction times.

\section{Discussion}

The findings support the prediction that individuals' self-evaluations can be influcnced by very minimal exposures to positive and negative evaluative stimuli. Graduate students' evaluative ratings of their own research ideas tended to be lower following exposure to their director's scowling face than following a postdoctoral fellow's approving face. Presumably the expressions primed cognitive structures representing evaluative interpersonal experiences, and these structures guided the selfevaluation process accordingly.

Some shortcomings of this initial study are obvious. The limited number of graduate students in this department did not allow for a sample size large enough to support a full range of statistical analyses. One question left unaddressed is the direction of effect: the design does not allow a conclusive assertion of whether it is the disapproving or the approving stimulus which is accounting for most of the variance in selfevaluations. Inspection of the means actually may suggest that the approval stimulus accounts for much of the variance, however, it is not possible to test this given the lack of an adequate control condition. The pretest measures do not provide an adequate control because being assessed at the first trial only (i.e., not randomized across trials as the experimental stimuli were), they may have been subject to a trials effect where subjects simply rated their first ideas more critically for some reason. The pretest condition did serve to establish that there were no 
significant differences between groups at that point, but in our second study we instituted a more fully appropriate control condition.

Second, rather than priming different cognitive structures representing particular types of interpersonal relationships it may be that it was simply the pleasantness or unpleasantness of the expressions depicted on the slides that influenced self-evaluations, by inducing a global positive or negative mood (e.g., Isen, 1984). A second study was conducted to address some of these issues, as well as to replicate the basic phenomenon.

\section{STUDY 2}

In order to replicate Study 1 with a somewhat larger sample size, it was necessary to identify a new population with a recognizable authority figure. After discussions with a number of people (including the chaplain at the Roman Catholic college affiliated with the University of Waterloo), we elected to study whether Catholic students might be affected by a presentation of a moderately disapproving picture of Pope John Paul II. In an effort to create a context where the Pope's evaluations might be particularly relevant, and to build on previous research, we focused on Catholic women responding in a context of somewhat permissive sexuality (using materials previously employed by Baldwin \& Holmes, 1987).

As well as replicating Study 1, we tried to address some of the issues raised there. First, rather than comparing a disapproval prime with an approval prime, which leaves the direction of effect unspecified, we decided to focus on the disapproval prime in comparison with a neutral control condition.

Second, it seemed important to rule out the possibility that the positive and negative expressions on the stimulus slides simply may have cued either globally good or globally bad moods, which then were reflected in the self-evaluations. This possibility was addressed by including a condition in which subjects were exposed to a disapproving picture of a person they did not know. As Manis (1955) and Rosenberg (1973) have pointed out, the sense of self is generally influenced more by the evaluations of certain people whose opinion one respects or whose approval one desires, than by the evaluations of less personally significant others. A familiar authority figure should therefore have a greater effect on the reflected appraisal process than an unfamiliar other. If the mood-extraction interpretation is correct, however, only the valence of expressions should make a difference, rather than the personal significance of the others. As a test of the importance of personal significance, while some subjects were exposed to the face of the Pope, some subjects were exposed instead to the photo used in Study 1 of the disapproving face of Robert Zajonc, a picture which for them would not represent a significant other and so should have less impact. 
To allow an important supplementary test of the significance issue, subjects also were asked how much they practiced their religion. It was expected that an exposure to the Pope's disapproving face would have a greater effect for subjects who were actively involved in their religion, and for whom the Pope truly would be a highly significant other.

\section{Method}

\section{Subjects}

Forty-six Catholic undergraduate women at the University of Waterloo volunteered to participate in the study. Most (25) were located through the psychology department's mass testing package in which students were asked to indicate their religious affiliation and to rate their degree of involvement in their religion (see the Measures section below). These subjects received course credit for their participation. As recruitment became more difficult due to an unexpectedly low number of Catholic women in the Introductory Psychology class, potential subjects were located through previous subjects, personal acquaintance, and the Roman Catholic-affiliated campus residence. Special care was taken to ensure that all of the subjects were unaware that they were preselected with respect to religious affiliation.

A maximum of four subjects were tested per session, by either a male $(n=16)$ or female $(n=30)$ experimenter. Each experimenter ran approximately equal numbers of subjects in each experimental condition.

\section{Materials and Apparatus}

Stimuli were presented using a Scientific Prototype Three-field Tachistoscope. All stimuli were presented on $15 \mathrm{~cm} \times 10 \mathrm{~cm}$ cards. Subjects were exposed to color photographs of the face of either Pope John Paul II or Robert Zajonc (an unfamiliar other), or else a plain white card. Attempts were made to match the pictures on size, coloring, and the negativity of the disapproving expression. Both pictures were frontal shots with the head slightly tilted and the eyes directed toward the camera.

\section{Stimulus Presentations}

The forward masking procedure recently described by Bornstein et al. (1987) was adoptcd as a method of presenting the stimuli. These authors also used pictures of faces as stimuli, to produce a subliminal mere exposure effect, and provide discrimination and self-report tests of subjects' awareness levels following the forward masking procedure.

The illumination of both the mask and stimulus fields when measured with a white card was set at $15 \mathrm{fl}$. For each stimulus exposure, a blank energy field mask was illuminated for $3 \mathrm{~s}$, followed by a 4-ms exposure of the stimulus. ${ }^{2}$ There were five exposures, $5 \mathrm{~s}$ apart.

${ }^{2}$ We attempted to verify exposure times using a silicon phototransistor interfaced with a Tektronix oscilloscope (model D11). Although the peak of the presentation curve at the 4-ms setting was clearly within the 4-ms time interval, there was a fairly gradual decay such that some measurable light was present as late as $10-14 \mathrm{~ms}$. It should be pointed out that the same ambiguity would likely be found in other reports that use tachistoscopes without testing decay rates, such as Bornstein et al. (1987), who used the same model of tachistoscope at the same 4-ms setting. As work in the area of brief exposures progresses, researchers will need to verify more carefully the accuracy of exposure durations. 


\section{Procedure}

Subjects first signed consent forms, and then completed a preliminary questionnaire package. This package contained some exploratory personality measures ${ }^{3}$ and two written passages. They were instructed to read the passages carefully, as they would be given one of them to evaluate later in the session. One passage was a filler story about a local park area, and the other described a woman's sexual dream. This sexual passage was neither explicit nor erotic, but did portray a permissive attitude toward sexuality. Baldwin and Holmes (1987) found the passage to be acceptable and enjoyable to many undergraduate women. In the present study, the passage was used to establish a context of sexuality, with the expectation that this might make subjects more reactive to the disapproving Pope stimulus.

When the subjects had finished reading the sexual passage, the experimenter escorted them to a second room which contained the tachistoscope. The experimenter explained that subjects would be exposed to five brief flashes of light, after which they were to return to the other room and complete a second questionnaire which they would find there. Subjects were then informed that in order to control for experimenter bias, they were to complete the remainder of the study without any interaction with the experimenter. The experimenter then moved behind a partition and randomly selected each subject's stimulus condition, exposing them to either pictures of Pope John Paul II or Robert Zajonc (an unfamiliar other), or else a blank card. Note that random assignment at this point allowed the experimenter to be blind to the subject's condition throughout the first phase of the experiment when interaction was required.

After they completed the second questionnaire, which contained the dependent measures (see below), subjects were fully debriefed. Due to the personal nature of some aspects of the study, special care was taken to inform subjects that the experiment was to examine a temporary effect, a slight shift in how subjects felt about themselves which would probably not represent their most stable day-to-day feelings about themselves, their sexuality, or their religion.

\section{Measures}

As a check of whether subjects were aware of seeing the stimulus slides, they first were asked to "please describe what you thought you saw in the $t$ scope."

As a measure of momentary self-concept, they then rated themselves on 15 nine-point bipolar adjective scales. Five adjective pairs were chosen to represent the domain of general morality (e.g., honest/dishonest, immoral/moral), five pairs were chosen to represent competency (e.g., intelligent/unintelligent, talented/untalented), and five pairs were chosen to represent anxiety (e.g., tense/at ease, calm/anxious). Each pair was randomly assigned to anchor positions, and the 15 items were randomly ordered.

After completing the self-conception inventory, subjects rated the enjoyableness and quality of the sexually permissive passage (see Baldwin \& Holmes, 1987, for questions).

Finally, as an indirect measure of how significant an authority the Pope would be to them, subjects reported on a nine-point scale ranging from "nonpracticing" to "practicing", the degree to which they considered themselves to be involved in their religion. This was exactly the same question that subjects who were recruited through departmental masstesting had completed at the beginning of term.

${ }^{3}$ As part of the honors theses on which this article is partly based, subjects were asked to complete the Self-Consciousness Scale (Fenigstein, Scheier, \& Buss, 1975) and a selfesteem scale (Rosenberg. 1965). Neither scale showed interpretable effects, and they will not be discussed further. 


\section{Results}

Reports of what subjects felt they saw in the tachistoscope uniformly described the blank screen that was exposed prior to the experimental stimuli. No subject reported anything that indicated they may have been aware of the stimulus slide (cf. Bornstein et al., 1987).

\section{Self-Conceptions}

The major dependent measure was the index of momentary self-concept. The subject's rating of each adjective pair was assigned a score out of nine, with higher numbers representing the more positive end of the scale. Competency, anxiety, and morality subscales were computed as the mean of the five items in each category. These subscales showed a fairly high degree of intercorrelation, average pairwise $r=.59$, probably indicating a global self-evaluative response. For the first set of analyses, therefore, an overall self-conceptions score was calculated as the average across all 15 items. High scores represented generally positive self-ratings.

Preliminary analyses revealed a significant experimenter effect, $F(2$, $34)=4.75, p<.05$, indicating that subjects rated themselves less positively in the presence of the male as opposed to the female experimenter. This effect did not interact with either of the independent variables, however, and will not be discussed further.

A 3 (condition: control/Pope/unfamiliar other) $\times 2$ (level of practicing: high/low) analysis of variance was performed on self-conception scores. Subjects were designated as high or low practicing following a median split procedure based on their postexperiment ratings of their involvement in their religion. ${ }^{4}$ The main effect for experimental condition was

\footnotetext{
${ }^{4}$ Because level of practicing is to be treated as an independent variable, it ideally would have been measured before each subject participated in the study. Difficulties in recruiting an adequate number of subjects prevented this, however, and premeasures were available for only 25 of the 46 subjects. Rather than give the measure to the remaining subjects prior to or at the beginning of the experimental session (which would alert all subjects to the relevance of religion to the study), or at a later time (after they had been debriefed), we decided to administer the measure at the very end of the session, before debriefing. Treating this type of measure as an independent variable requires some evidence that it was not affected by the experimental treatments. This postmeasure was correlated with prescores that were available from some subjects. $r(23)=.79, p<.01$. There were no significant results for condition in either a repeated measures analysis of variance of preand post-test scores $(n=25), F s<1.7, n s$., or independent analyses of variance for pretest scores $(n=25)$, or post-test scores $(n=46), F \mathrm{~s}<1.5, n s$. Moreover, if analyses of the self-concept score are carried out only on data from subjects providing practicing premeasures the pattern of data is quite similar, and planned contrasts (in place of the ANOVA which obviously is weakened by the lower $n$ ) yield similar results. Finally, if post-test scores are replaced by pretest scores for those subjects for whom they were available, and the median split procedure on the whole sample then is based on this hybrid score, the self-concept ANOVA main effect and interaction remain significant.
} 
TABLE 2

Overall Self-Conceptions and Self-Conception Subscales by Stimulus Conditions

\begin{tabular}{lccc} 
& \multicolumn{3}{c}{ Stimulus condition } \\
\cline { 2 - 4 } Measure & Control & Pope & $\begin{array}{c}\text { Unfamiliar } \\
\text { other }\end{array}$ \\
\hline $\begin{array}{l}\text { Overall self-conceptions } \\
\text { Subscales }\end{array} \quad$ & 7.02 & 6.30 & 7.09 \\
$\quad$ Competency & & & \\
$\quad$ Anxiety & 6.97 & 6.00 & 6.77 \\
$\quad$ Morality & 6.43 & 5.41 & 6.73 \\
$(n)$ & 7.65 & 7.50 & 7.77 \\
& $(15)$ & $(16)$ & $(15)$ \\
\hline
\end{tabular}

Note. Higher numbers represent more positive ratings.

significant, $F(2,40)=3.38, p<.05$ (see Table 2). Contrasts using the mean square error estimate from the ANOVA showed that whereas the Pope group reported significantly lower self-concept scores than control, ${ }^{5}$ $t(40)=2.09, p<.05$, the unfamiliar-other group did not differ from control, $t<1$. As predicted, only the group exposed to the disapproving face of a personally significant other showed a lowered evaluation of self.

The main effect for level of practicing was not significant, $F<1$, however the interaction between condition and practicing was significant, $F(2,40)=3.41, p<.05$ (see Table 3 ). To clarify this interaction, tests were done between experimental and control groups at each level of practicing. In the low practicing group, neither experimental group was different from control, $t \mathrm{~s}<1$. In the high practicing group, those in the Pope condition did report lower self-concepts than those in control, $t(40)=2.30, p<.05$, but those in the unfamiliar-other group did not differ from control, $t<1$. The effect of the Pope stimulus, therefore, was limited to those subjects who considered themselves highly involved in their religion, and for whom the Pope presumably would be a highly significant evaluative authority.

\section{Self-Conceptions Subscales}

Although the three subscales of the self-conceptions measure showed patterns of means quite similar to the overall score, it is important to examine the subscales, both because they may be measuring somewhat different constructs and to ensure that the overall effect is not due entirely to one subset of measures (e.g., anxiety, cf. Robles et al., 1987). When the $3 \times 2$ ANOVA was conducted on the competency subscale (the

${ }^{5}$ All $t$ tests reported for Study 2 are two-tailed. 
TABLE 3

Overall Self-Concertions and Self-Conception Subscales by Stimulus Condition and Level of Practicing

\begin{tabular}{|c|c|c|c|c|c|c|}
\hline \multirow[b]{2}{*}{ Measure } & \multicolumn{3}{|c|}{ Low Practicing } & \multicolumn{3}{|c|}{ High Practicing } \\
\hline & Control & Pope & $\begin{array}{l}\text { Unfamiliar } \\
\text { other }\end{array}$ & Control & Pope & $\begin{array}{c}\text { Unfamiliar } \\
\text { other }\end{array}$ \\
\hline \multicolumn{7}{|l|}{ Overall } \\
\hline Self-conceptions & 6.93 & 6.70 & 6.64 & 7.11 & 6.00 & 7.77 \\
\hline \multicolumn{7}{|l|}{ Subscales } \\
\hline Competency & 6.97 & 6.14 & 6.42 & 6.97 & 5.89 & 7.30 \\
\hline Anxicty & 6.45 & 5.89 & 6.11 & 6.40 & 5.04 & 7.67 \\
\hline Morality & 7.37 & 8.06 & 7.40 & 7.97 & 7.07 & 8.33 \\
\hline$(n)$ & (8) & (7) & (9) & (7) & (9) & (6) \\
\hline
\end{tabular}

Note. Higher numbers represent more positive ratings.

average across the five competency-relevant items), there was a significant main effect for condition, $F(2,40)=4.21, p<.05$ (see Table 2). For the anxiety subscale, the main effect for condition was significant, $F(2,40)=3.61, p<.05$ (see Table 2 ), and the practicing by condition interaction was marginally significant, $F(2,40)=2.64, p=.09$ (see Table 3). On the morality subscale, neither main effect was significant, but the practicing by condition interaction was, $F(2,40)=4.27, p<$ .05 (see Table 3).

\section{Story Evaluations}

There were no significant effects in analyses of the evaluations of the sexual passage. This result will be discussed below.

\section{Discussion}

The results of this study conceptually replicate those of Study 1, and address some additional issues as well. Two methods of assessing the relevance of personal significance supported the notion that exposures to truly significant others can have an effect on self-conception, when exposure to a nonsignificant other does not. Catholic women reported lower self-evaluations overall following exposure to the Pope's disapproving face, but not following exposure to an unfamiliar other's disapproving face. Moreover, the effect for the Pope was only evident for subjects who reported that they practiced their religion on a regular basis.

The finding that personal significance of the stimulus other is a crucial factor in the phenomenon effectively rules out some simple alternative hypotheses, such as that the disapproving Zajonc stimulus was effective in Study 1 simply by virtue of portraying a negative expression. Rather, it seems that a brief exposure to the disapproving face of a recognized 
significant other accesses pre-existing structures representing negative evaluation by people who are personally important. The effect for personal significance is relevant to the issue of whether automatic priming effects in general reflect cognitive or affective processes (e.g., Bargh, Bond, Lombardi, \& Tota, 1986; Erdley \& D'Agostino, 1988). While it may be that subjects' self-evaluative mood was fairly globally negative following exposure to the Pope stimulus, as evidenced by the similar pattern of means across subscales, there was no evidence of a parallel negative response following the strongly negative affective stimulus picture of an unfamiliar other. Recent research has suggested that face recognition is carried out separately from expression identification (Bruce, 1986; Bruce \& Young, 1986; Young, McWeeny, Hay, \& Ellis, 1986); the differential findings for the two experimental stimuli demonstrate that face recognition is a necessary component of the present priming effect. The effect was therefore due at least in part to the accessibility of the construct representing disapproval by the significant other, rather than simply to the unconscious extraction of the emotional content displayed in the stimulus expressions.

Indeed, one might even speculate that recognition of the stimulus person was a sufficient as well as a necessary condition for the effect, that is, that any picture of a familiar person or a significant authority figure, regardless of evaluative expression, would have produced selfcriticism. This argument should hold particularly if the authority figure is typically associated with negative responses, either because of a history of negative interactions or the fact that the person is seen as holding evaluative standards that are difficult to satisfy. If one assumes that both the Pope (in this study) and Robert Zajonc (in Study 1) may have been perceived by subjects as being tough evaluators, it is not possible to disentangle the effects of the disapproving expression and a negative expectancy about the stimulus person. While it intuitively does not seem likely to us that subjects in Study 1 would have rated their ideas quite as poorly if they had seen a picture of their departmental director beaming with enthusiastic admiration, this possiblity can not be ruled out by the present data and remains an important question for further research.

A potential alternative explanation for the results might be that the Pope stimulus actually was more menacing than the Zajonc stimulus, and this could explain the greater effect on subjects' self-evaluations. In an informal sampling, however, 10 people unanimously rated the disapproving expression of the Pope stimulus as only equally or even slightly less severe than that of the Zajonc stimulus, rather than more so.

One finding of interest was that the different self-conception subscales showed slightly different effects. The presence of a main effect for stimulus condition on competency as well as anxiety ratings indicates that the stimuli probably are not simply priming anxiety, as has been shown 
previously with brief exposures of frightening scenes (Robles et al., 1987). Also, the evidence of an interaction between condition and degree of practicing on the morality subscale implicates particular value systems rather than a global evaluative response: only those subjects who subscribed to the value system represented by the Pope were affected by exposure to his disapproving face. Although the different patterns on the subscales are intriguing, the fairly high correlations among measures, the fact that the subscales were derived from only five items as opposed to 15 items for the overall scale, as well as the rather low $n$ for the interaction comparisons, stand as a caution against overinterpreting these differences before they are replicated.

Although we did anticipate some effects on evaluations of the sexual passage, the null findings may not be entirely surprising. Part of this may be that the self-conceptions measure diffused some of the effects of the stimuli, or that the effect of the prime simply dissipated over time. Also, other studies (e.g., Srull \& Wyer, 1980) have found that primes are not effective in changing interpretations of information that has already been processed, as the sexual story had been.

\section{GENERAL DISCUSSION}

The results of the present studies are consistent with the hypothesis that a person's momentary sense of self can be shaped by cognitive structures representing significant interpersonal information. The studies raise many interesting questions, and suggest many important directions in which to proceed with subsequent research in this area.

There are a number of possible interpretations of the findings, each suggesting a different route for future research. One possibility is that the primes directly activated an affective process of some kind, rather than cognitive structures (e.g., Bower, 1981; Zajonc, 1980). Affective and motivational factors are certainly critically important in self as well as interpersonal processes, and our emphasis on cognitive factors only represents the state of development of the current information-processing paradigm, rather than any commitment to the primacy of cognition. Study 2 did address the necessity for recognition of the stimulus person, but beyond that it is not clear to what extent purely cognitive structures could be said to mediate the effects. In any event, we suspect that selfevaluative cognitions are always "hot" cognitions, laden with affective implications which play an important role in determining subsequent processing. Until social cognitive models are integrated more fully with affective, motivational, and even motoric (e.g., Zajonc, 1988) factors, it would be wise to assume the important interdependency of all of these elements, and that experiencing oneself as being disapproved of by a significant other presumably involves thinking that one is disapproved 
of, feeling disapproved of, and being motivated to avoid disapproval and garner approval.

A second interpretation of the findings is that they may not represent a reflective appraisal process at all, but rather a social comparison process (Festinger, 1954). ${ }^{6}$ Rather than priming disapproval by a significant authority, the stimuli may have primed a high status other, compared with whom subjects felt inferior and less worthy. Although this interpretation cannot be ruled out in the present studies, it would not apply to the related research reviewed earlier (Baldwin \& Holmes, 1987), in which visualization primes produced more specific self-evaluative effects over a range of content areas. Not all questions can be addressed by any two studies, and the possibility of social comparison processes functioning outside conscious awareness must remain a question for further research.

Relationship schemas. A third interpretation of the findings is that the primes did, in fact, activate structures representing the experience of being disapproved of by a significant other. The exact nature of the underlying structures is far from clear, as indicated in the earlier discussion of the relative importance of expectations regarding specific significant others versus the expression depicted on an experimental prime. Although the findings can not answer unequivocally these and other questions about what structures underly the phenomenon, perhaps some speculation is in order about what might be going on.

One might speculate that a habitual pattern of interacting, observed over time in a relationship, can become represented as procedural knowledge in the form of an interaction script that represents a regular pattern of relating between self and other, along with a self-schema and a schema or prototype for the significant other. Rather than trying to understand the process of self-conception by focusing on the self-schema or the other-schema in isolation, it would be wise to consider the entire relationship.

There might be advantages in examining the notion of relationship schemas or interpersonal schemas, defined as cognitive structures representing regularities in interpersonal interaction. Over one's lifetime, any experiences of negative evaluative feedback from authority figures could become organized into a relationship schema of, for example, "being disapproved of for an incompetent performance or immoral act" (the type of schema that was assumed to be primed by the stimuli in the present studies). This learned interaction pattern might take its place beside others such as, "being approved of for acting generously," "being feared and avoided after expressing anger," or "being treated with respect when one asserts one's position." Similar concepts have been discussed elsewhere, particularly in the clinical literatures (e.g., Blatt \&

${ }^{6}$ We thank Mel Lerner and Rich Ennis for pointing out this hypothesis. 
Lerner, 1983; Horowitz, 1979, 1988; Luborsky, 1977, 1988; Mayman \& Faris, 1960; Stern, 1985; Tomkins, 1980), and it is a useful idea for social cognitive research as well.

There is a long tradition in the social psychological as well as clinical literatures that interpersonal factors play an important role in self-conception. Much past research has focused on the impact of social factors either in the environment or as represented internally in an imaginary private audience (e.g., Baldwin \& Holmes, 1987). The relationshipschema notion suggests that the interpersonal context for self-construal may be determined by cognitive structures based on overlearned interpersonal situations.

If so, it may be that past construals of self as competent, immoral, or whatever, as represented in stable self-schemas, have only a limited direct impact on a person's momentary sense of self. Rather, the sense of identity might always be constructed anew as an emergent product of a matrix of salient interpersonal information, from both ongoing interactions and accessible cognitive structures. And, as the present studies indicate, these structures may be primed by stimuli that are very subtle, or even outside of conscious awareness.

The present research is very compatible with another body of work also drawn from the literature on self-conception and its roots in interpersonal experience. A series of important studies by Higgins and his colleagues (see Higgins, 1987, for a review) has indicated that specific self-evaluative emotions such as depression and anxiety may be caused by cognitively accessible discrepancies between one's view of self and the evaluative standards held by self and others. Indeed, within the framework of Self Discrepancy Theory the present studies could be seen as aimed at priming the significant other "standpoints on the self" associated with particular evaluative standards, in contrast with other studies in which standards and discrepancies are primed more directly (e.g., Higgins, Bond, Klein, \& Strauman, 1986; Strauman \& Higgins, 1987). This comparison illustrates an important difference in emphasis between perspectives: While evaluative standards are obviously critical features in self-conception, we believe it would be unwise to treat standards as if, once learned, they become functionally autonomous from the interpersonal context in which they were established. As Miller (1963) points out, "People do not internalize abstract norms, but images of themselves in concrete relationships with specific people or groups" (p. 666). Evaluative standards may be the most proximal causes of self-evaluative distress, but, as Higgins, Klein, and Strauman (1985) acknowledge, standards are only important because they have had interpersonal consequences. We would advocate concentrating more fully on the interpersonal context, which will allow the study of such evaluation-relevant issues as the degree to which a particular other is emotionally significant 
(e.g., Klein \& Higgins, 1984, cited in Higgins, 1987), or the degree to which approval by others is experienced as conditional on successful performance (Baldwin \& Holmes, 1987, Study 2). Moreover, it is important to bear in mind that evaluation is not the only consequential aspect of self-conception and interpersonal relationship: Future research into the relationship-schema notion could investigate other issues not obviously related to evaluation such as whether an internalized relationship is characterized by dependency versus autonomy (e.g., Baldwin \& Shaw, 1988), or the presence versus absence of hostility (cf. psychodynamic theories of depression; e.g., Freud, 1917).

Further research is clearly required to assess more directly the relationship schema notion. As consensus grows in the literature on the best methods for studying automatic priming, additional work will also be needed to determine more clearly the effects of conscious and nonconscious primes of interpersonal information. In the future, social cognitive methodologies will be useful in experimentally investigating the extremely important question of how individuals' dysfunctional, problematic relationship schemas can be modified, and what makes them more flexible vs rigid. The first step, however, is to learn more about what type of information is stored in relationship schemas, how exactly it is represented, and how it influences the sense of self.

\section{REFERENCES}

Baldwin, M. W., \& Holmes, J. G. (1987). Salient private audiences and awareness of the self. Journal of Personality and Social Psychology, 53, 1087-1098.

Baldwin, M. W., \& Shaw, B. F. (1988). Interpersonal dysfunction and self-consciousness in relation to dependency and self-critical factors in depression. Unpublished manuscript.

Bargh. J. A., Bond, R. N., Lombardi, W. J., \& Tota, M. E. (1986). The additive nature of chronic and temporary sources of construct accessibility. Journal of Personality and Social Psychology, 50, 869-878.

Bargh, J. A., \& Pietromonaco, P. (1982). Automatic information processing and social perception: The influence of trait information presented outside of conscious awareness on impression formation. Journal of Personality and Social Psychology, 43, 437-449.

Blatt, S. J., \& Lerner, H. (1983). Investigations in the psychoanalytic theory of object relations and object representations. In J. Masling (Ed.), Empirical studies of psychoanalytic theories (Vol. 1, pp. 189-249). Hillsdale, NJ: Erlbaum.

Bornstein, R. F., Leone, D. R.. \& Galley, D. J. (1987). The generalizability of subliminal mere exposure effects: Influences of stimuli perceived without awareness on social behavior. Journal of Personality and Social Psychology, 53, 1070-1079.

Bower, G. H. (1981). Mood and memory. American Psychologist, 36, 129-148.

Bruce, V. (1986). Influences of familiarity on the processing of faces. Perception, 15, 387397.

Bruce, V., \& Young, A. (1986). Understanding face recognition. British Journal of Psychology, 77, 305-327.

Cheesman, J., \& Merikle, P. M. (1985). Word recognition and consciousness. In D. Besner, T. G. Waller, \& G. E. MacKinnon (Eds.), Reading research: Advances in theory and practice (Vol. 5, pp. 311-352). New York: Academic Press. 
Erdley, C. A., \& D'Agostino, P. R. (1988). Cognitive and affective components of automatic priming effects. Journal of Personality and Social Psychology, 54, 741-747.

Fenigstein, A., Scheier, M. F., \& Buss, A. H. (1975). Public and private self-consciousness: Assessment and theory. Journal of Consulting and Clinical Psychology, 43, 522-527.

Festinger, L. (1954). A theory of social comparison processes. Human Relations, 7, 117140.

Freud, S. (1917). Mourning and melancholia. The standard edition of the complete psychological works of Sigmund Freud (Vol. 14, pp. 237-248). London: Hogarth Press.

Higgins, E. T. (1987). Self-discrepancy: A theory relating self and affect. Psychological Review, 94, 319-340.

Higgins, E. T., Bond, R. N., Klein, R., \& Strauman, T. (1986). Self-discrepancies and emotional vulnerability: How magnitude, accessibility and type of discrepancy influence affect. Journal of Personality and Social Psychology, 51, 1-15.

Higgins, E. T., \& King, G. (1981). Accessibility of social constructs: Information-processing consequences of individual and contextual variability. In N. Cantor \& J. F. Kihlstrom (Eds.), Personality, cognition, and social interaction (pp. 69-121). Hillsdale, NJ: Erlbaum.

Higgins, E. T., Klein, R., \& Strauman, T. J. (1985). Self-concept discrepancy theory: A psychological model for distinguishing among different aspects of depression and anxiety. Social Cognition, 3, 51-76.

Holender, D. (1986). Semantic activation without conscious identification in dichotic listening, parafoveal vision, and visual masking: A survey and appraisal. The Behavioral and Brain Sciences, 9, 1-66.

Horowitz, M. J. (1979). States of Mind. New York: Plenum.

Horowitz, M. J. (1988). Psychodynamic phenomena and their explanation. In M. J. Horowitz (Ed.). Psychodynamics and cognition (pp. 3-20). Chicago: University of Chicago.

Isen. A. M. (1984). Toward understanding the role of affect in cognition. In R. Wyer \& T. Srull (Eds.), Handbook of social cognition (pp. 174-236). Hillsdale, NJ: Erlbaum.

Kunst-Wilson, W. R., \& Zajonc. R. B. (1980). Affective discrimination of stimuli that cannot be recognized. Science, 207, 557-558.

Luborsky, L. (1977). Measuring a pervasive psychic structure in psychotherapy: The core conflictual relationship theme. In N. Freedman \& S. Grand (Eds.), Communicative structures and psychic structures (pp. 367-395). New York: Plenum.

Luborsky, L. (1988). Recurrent momentary forgetting: Its content and its context. In M. J. Horowitz (Ed.), Psychodynamics and cognition (pp. 223-251). Chicago: University of Chicago.

Manis, M. (1955). Social interaction and the self-concept. Journal of Abnormal and Social Psychology, 51, 362-370.

Mayman, M., \& Faris, M. (1960). Early memories as expressions of relationship paradigms. American Journal of Orthopsychiatry, 30, 507-520.

Mead, G. H. (1934). Mind, self, and society. Chicago: University of Chicago Press.

Miller, D. R. (1963). The study of social relationships: Situation, identity, and social interaction. In S. Koch (Ed.), Psychology: A study of a science (Vol. 5, pp. 639-737). Toronto: McGraw-Hill.

Robles, R., Smith, R., Carver, C. S., \& Wellens, A. R. (1987). Influence of subliminal visual images on the experience of anxiety. Personality and Social Psychology Bulletin, $13,339-410$.

Rosenberg, M. (1965). Society and the adolescent self-image. Princeton, NJ: Princeton University Press.

Rosenberg, M. (1973). Which significant others? American Behavioral Scientist, 16, 829860. 
Shevrin, H., Smith, W. H., \& Fitzler, D. E. (1971). Average evoked response and verbal correlates of unconscious mental processes. Psychophysiology, 8, 149-162.

Silverman, L. H. (1983). The subliminal psychodynamic activation method: Overview and comprehensive listing of studies. In J. Masling (Ed.), Empirical studies of psychoanalytic theories (pp. 69-100). Hillsdale, NJ: Erlbaum.

Srull, T. K., \& Wyer, R. S. (1980). Category accessibility and social perception: Some implications for the study of person memory and interpersonal judgments. Journal of Personality and Social Psychology, 38, 841-856.

Stern, D. N. (1985). The interpersonal world of the infant. New York: Basic Books.

Strauman, T. J., \& Higgins, E. T. (1987). Automatic activation of self-discrepancics and emotional syndromes: When cognitive structures influence affect. Journal of Personality and Social Psychology, 53, 1004-1014.

Sullivan, H. S. (1953). The interpersonal theory of psychiatry. New York: Norton.

Tomkins, S. S. (1980). Script theory: Differential magnification of affects. In H. E. Howe, Jr., \& M. M. Page (Eds.), Nebraska symposium on motivation (Vol. 27). Lincoln: University of Nebraska.

Young, A. W., McWeeny, K. H., Hay, D. C., \& Ellis, A. W. (1986). Matching familiar and unfamiliar faces on identity and expression. Psychological Research, 48, 63-68.

Zajonc, R. B. (1980). Feeling and thinking: Preferences need no inferences. American Psychologist, 35, 151-175.

Zajonc, R. B. (1988). Prolegomena for the study of access to mental events: Notes on Singer's chapter. In M. J. Horowitz (Ed.), Psychodynamics and cognition (pp. 347359). Chicago: University of Chicago. 